\title{
下寒武统大林子组溶解蒸发岩系旋回层序 及渗流构造成因
}

\section{孟祥化 ${ }^{(1)}$ 葛 铭 ${ }^{(1)}$ 蔡国印 ${ }^{(2)}$ 旷红伟 ${ }^{(1)}$ 刘燕学 ${ }^{(1)}$}

(1)中国地质大学沉积盆地研究所, 北京 100083; (2)中国矿业大学资源系, 北京 100083. E-mail: mengxh@cugb.edu.cn)

《科学通报》第 44 卷第 16 期发表了《华北中新 元古代及早古生代地震灾变事件及与 Rodinia 的关 系》 ${ }^{11]}$ 一文 (以下简称《华北》), 涉及辽宁大连下寒 武统大林子组的成因问题. 我们曾先后于 1984 1986, $1993 \sim 1995$ 和 2001 年对该组地层进行过详细 的旋回层序、微层序和岩石学及微组构成因研究, 对 大林子组中段溶解蒸发岩系进行了几至几十厘米的 超微层单元逐层观测取样, 进行室内显微岩石组构 和化学组分分析. 本文按层序、岩石组构分析和比较 沉积学分析进行论述, 就《华北》所指大林子组发育 “臼齿构造”、“震积岩”及“震积序列”等问题进行 讨论.

\section{1 宏观层序特征}

下寒武统大林子组 ${ }^{[2 \sim 4]}$ 是由下部陆源碎屑岩段、 中部泻湖蒸发岩段和顶部浅海碳酸盐岩段构成的三 级层序. 本文重点研究的溶解蒸发岩亚层序形成于 陆相与正常海相亚层序之间的过渡时期, 相当于本 文的代表性剖面辽东半岛大连地区下寒武统大林子 组 ${ }^{[2 \sim 4]}$ 的中部岩段, 即大林子组 $\mathrm{IV}_{2} \sim \mathrm{IV}_{3}$ 亚层序(图 1), 其内部进一步可划分出由含石盐假晶的钙质、硅质砂 岩、粉砂-泥岩及少量泥灰质岩构成的 $\mathrm{V}$ 级旋回层序. $\mathrm{V}$ 级层序的顶面和底部岩层内均发育有巨型的石盐 假晶. 在亚层序 $\mathrm{IV}_{3}$ 内部发现有大量盐溶证据, 如盐 溶构造(图2(b))及同生滑动肠状构造(图 2(d)). 不同级 次和规模的干裂构造在韵律层中有规律地分布, 并 且可以见到盐溶滑动肠状禇皱被近垂直的干裂缝隙 (图 2(a))及管状体所切割(图 2(c), (d)). 因此, 它是经 过溶解作用改造的古盐盘蒸发盐层系。管状体是一 种沿干裂纹向下延伸变细的多角状管道, 其内部主 要由含石盐假晶的灰绿色及红色粉砂-泥质充填（图 1(a)，(c)，(d)). 层序中部的蒸发盐盘层段包括 JDS-1
至 JDS-19, 其层序内部韵律性十分明显, 韵律层厚 度变化为 $20 \sim 150 \mathrm{~cm}$. 每一个韵律层包括: 含石盐假 晶的钙质粗粒含长石石英砂岩、细石英粉砂岩和紫红 色、黄绿色钙质泥岩-泥质灰岩等单元:

底部单元 $\mathrm{a}$ : 厚度变化大, 不稳定, 厚 $0 \sim 20 \mathrm{~cm}$, 为含石盐假晶的钙质含长石石英砂岩层, 以石英砂 粒为主(占 $85 \% ＼mathrm{~ 90 \%) ~ 并 有 少 量 长 石(微 斜 长 石) . ~}$

中部单元 $\mathrm{b}$ : 厚 $10 \sim 100 \mathrm{~cm}$, 为黄绿色、紫红色 泥质页岩夹薄层状粉砂岩透镜体, 水云母粘土多为 针状、片状, 组成杂乱状或格子状排列的结构特征. 微薄层透镜状粉砂岩和泥质石英粉砂岩多为钙质胶 结或硅质胶结.

顶部单元 $\mathrm{c}$ 或 $\mathrm{d}$ : 厚 $5 \sim 50 \mathrm{~cm}$, 为灰黄色-淡粉红 色粉砂质泥岩和粉砂质页岩. 此单元中的紫红色粉 砂质泥岩具有十分发育的干裂构造(图 2(a)).

\section{2 岩石学成岩组构分析特征}

经显微镜组构分析和微观测试研究 ${ }^{[2]}, \mathrm{IV}_{3}$ 亚层 序内底部单元 a 中, 含有大量 $\mathrm{SiO}_{2}$ 立方体颗粒(石盐 假晶). 根据薄片粒度分析, 石英砂岩多具有双峰值 粒度分布特性, 石盐假晶发育雾心和方形环带 (图 $3(\mathrm{~b})$, (c)), 颗粒大小从 $0.01 \sim 0.1 \mathrm{~mm}$ 不等, 此外还有 很多大型至巨型石盐假晶群体呈雉形漏斗状产出, 最大的巨型假晶群直径可达 $4 \sim 5 \mathrm{~cm}$. 巨型石盐假晶 多呈突出状产出于下伏泥质岩单元顶部. c-d 单元和 底部 a 单元发育干裂纹构造和沿干裂纹延伸形成的 板状管状构造，同时还常见成岩后期因石盐石膏溶 解形成的肠状构造、溶洞构造和交代变形构造. 此外, 在中部单元 $\mathrm{b}$ 中, 浅灰色石英粉砂岩透镜体内发育有 大量微粒石盐假晶. 石英粉砂岩溶蚀结构十分发育, 并在石英粉砂岩透镜体层上下发育有小型溶洞和流 砂构造. 在顶部单元 $\mathrm{c}$ 的顶面上常形成有准同生玉髓 


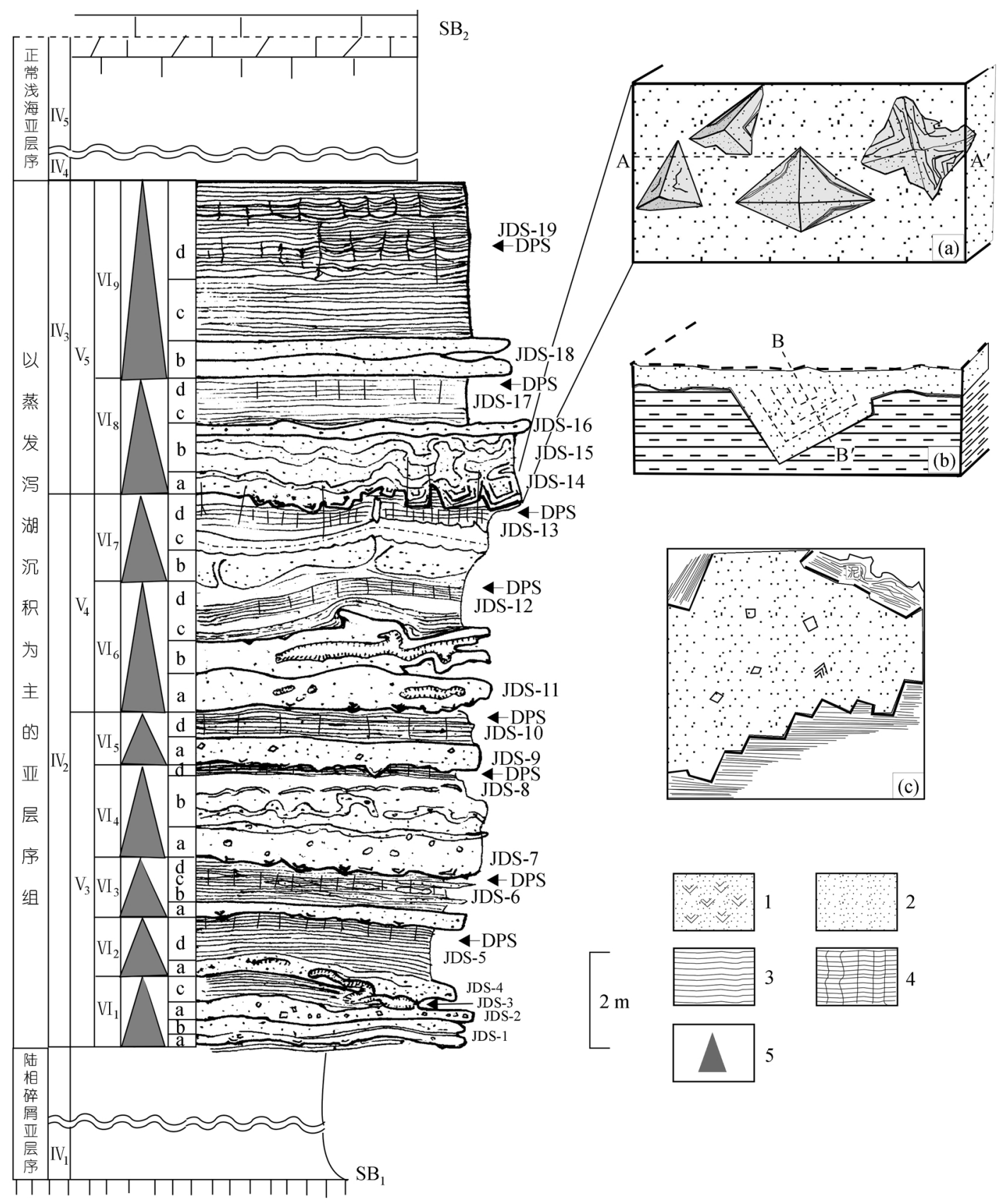

图 1 大连金石滩大林子组溶解蒸发岩亚层序

(a) 底面(JDS-14)素描图, 该层为盐溶微层序, 底部单元钻质粉砂岩底面出露石盐假晶(原大); (b) 垂直层序断面(图(a)的 A-A 剖面)素描图, 示石 盐假晶与砂质单元和泥质单元的分布关系 (1/2 原大); (c) 石盐假晶体内部充填物(图(b)的 B-B' 剖面): 细砂粒、粉砂及微石盐假晶(玉髓填充)( $1 / 4$ 原大). 1. 发育巨型石盐假晶的粗砂-细砂岩; 2. 发育微粒石盐假晶的含细砂粉砂岩; 3. 红褐色-绿色粉砂质页岩、泥岩; 4. 发育渗流管的红褐色灰绿色砂质页岩-泥灰岩; 5. 向上变浅序列. IV : 亚层序; V : 细层序; VI：微层序; DPS：溶解(渗流)构造; $\mathrm{SB}_{1}$ ： I 型层序界面; $\mathrm{SB}_{2}$ ： II 型层序界 面; JDS: 分层编码

呈石盐假铸模和由于受 $\mathrm{a}, \mathrm{b}$ 两单元的盐溶变形影响＼cjkstart种微观组构特征，详见素描图(图 1(a) (c))和显微照 产生的岩层弯曲和穿刺构造: 

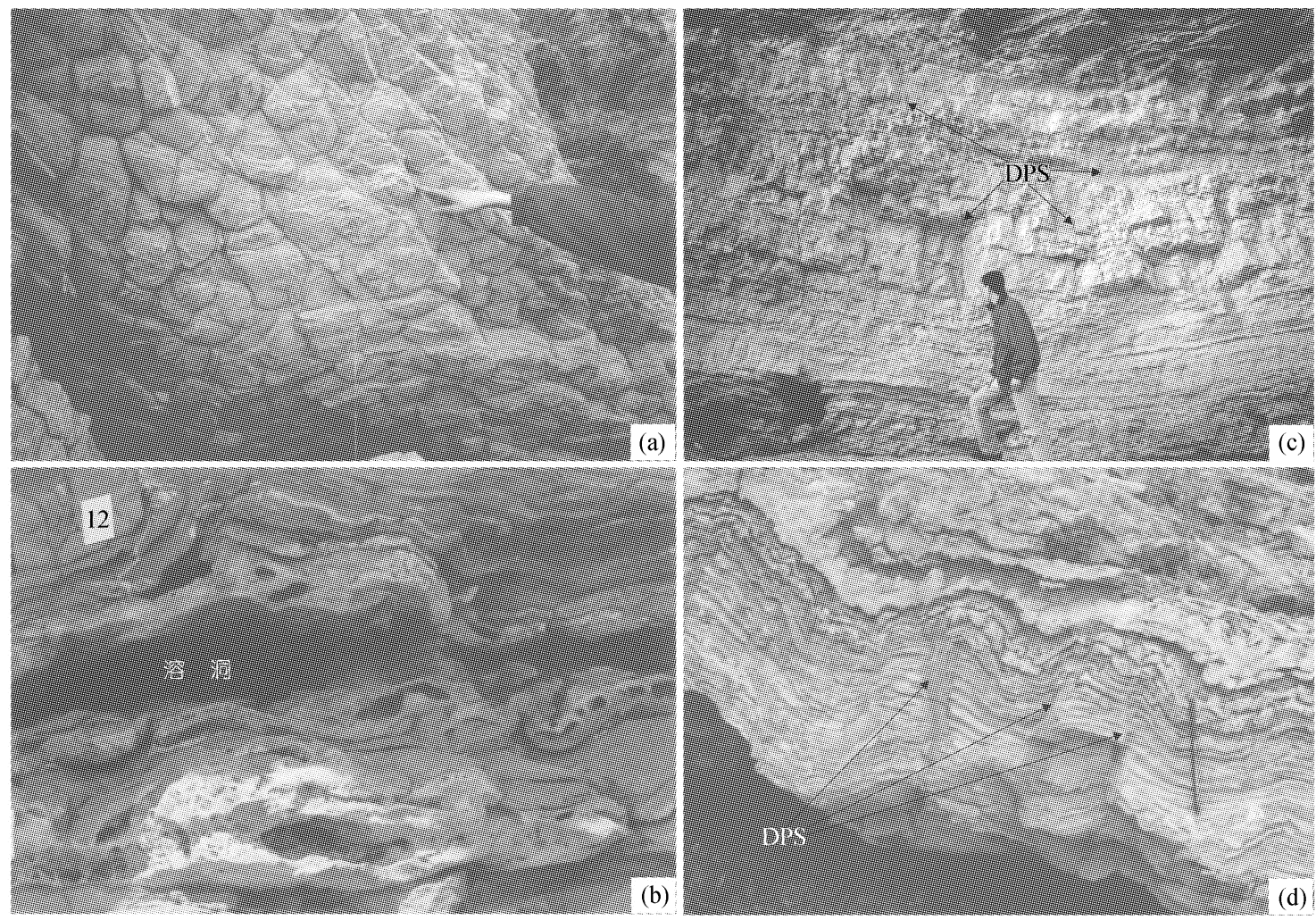

图 2 大连金石滩大林子组溶解蒸发岩层序宏观特征

(a) $€ \mathrm{~S} 2$ (下寒武纪第 2 个层序)旋回层序的 $\mathrm{VI}_{9}$ 单元(JDS-9): 紫红色钻质粉砂岩及泥岩互层, 向上颜色变浅, 发育干裂纹构造, 图为其底层面, 可 见清晰干裂纹构造; (b) $\in \mathrm{S} 2$ 旋回层序中部的局限蒸发泻湖亚层序组的 V 4 JDS11-JDS12 微层序单元(图 1), 由褐红色粉砂-细砂质泥岩透镜层构 成. 空洞处为原生石膏层溶蚀形成; (c) 局限蒸发泻湖亚层序组 JDS-19中细小的渗流管十分发育, 黄褐色白云质泥岩代表咸化泻湖, 常出现潜水 位下降作用; (d) 亚层序组 JDS13-JDS15 中沿干裂纹发育大型的渗流管(DPS)

石盐假晶结构有如下类型：(1) 石盐假晶被蛋白 石、玉髓和沉积石英交代充填结构; (2) 残留的原生纹 层状泥质白云石, 即残留白云石纹层结构; (3) 大型 硅质交代的石盐假晶堆叠结构: 漏斗状石盐假晶群; (4) 石盐假晶被硅质交代残留的泥状白云石结构. 这 些成岩假晶结构进一步说明了成岩期盐溶作用的 存在.

据化学分析和光谱半定量分析 ${ }^{[3]}$, a 单元的 $\mathrm{Sr}, \mathrm{B}$ 含量均偏高, $\mathrm{B} / \mathrm{Ga}=8, \mathrm{Sr} / \mathrm{Ba}=0.667$. 据有关分析资 料 ${ }^{[5]}$, 海相沉积物 $\mathrm{B} / \mathrm{Ga}$ 值为 $4.5 \sim 5.0$, 淡水相为 2.4 或 2.3 , 海相 $\mathrm{Sr} / \mathrm{Ba}=100.8$, 陆相样为 0.54 至 0.16 . 据 此分析, 本层序的样品应为海-陆相过渡的蒸发泻湖 环境.

由此可见, 该组 $\mathrm{IV}_{2}-\mathrm{IV}_{3}$ 亚层序属滨岸泻湖盐盘
沉积体系，可与华北地区早古生代 $\in S 1$ 层序 ${ }^{[2,6]}$ 如河 北昌平组、河南的朱珠砂洞组等蒸发盐层序 ${ }^{[5,7]}$ 属同 一层序地层单位，代表华北地台早寒武世早期区域 性的干旱蒸发气候周期事件 ${ }^{[6]}$.

\section{3 比较沉积学和沉积模式}

据相关报道，美国、墨西哥、埃及及波利维亚等 国家的全新世盐盘(Salt pan)沉积中, 亦均识别出包 括盐溶渗流等盐层组构标志系列 ${ }^{[8 ~ 11]}$. 这些研究成果 也证实, 渗流构造的长度与古潜水面下降深度相关, 古潜水位下降深度越大，渗流构造则越粗大，除了灰 绿色的充填物外, 主要为粉砂泥质物. 另据文献 [11], 在西西里岛 Realmonte 盐矿层中发现长达 1 2 m 以 上的渗流构造. 


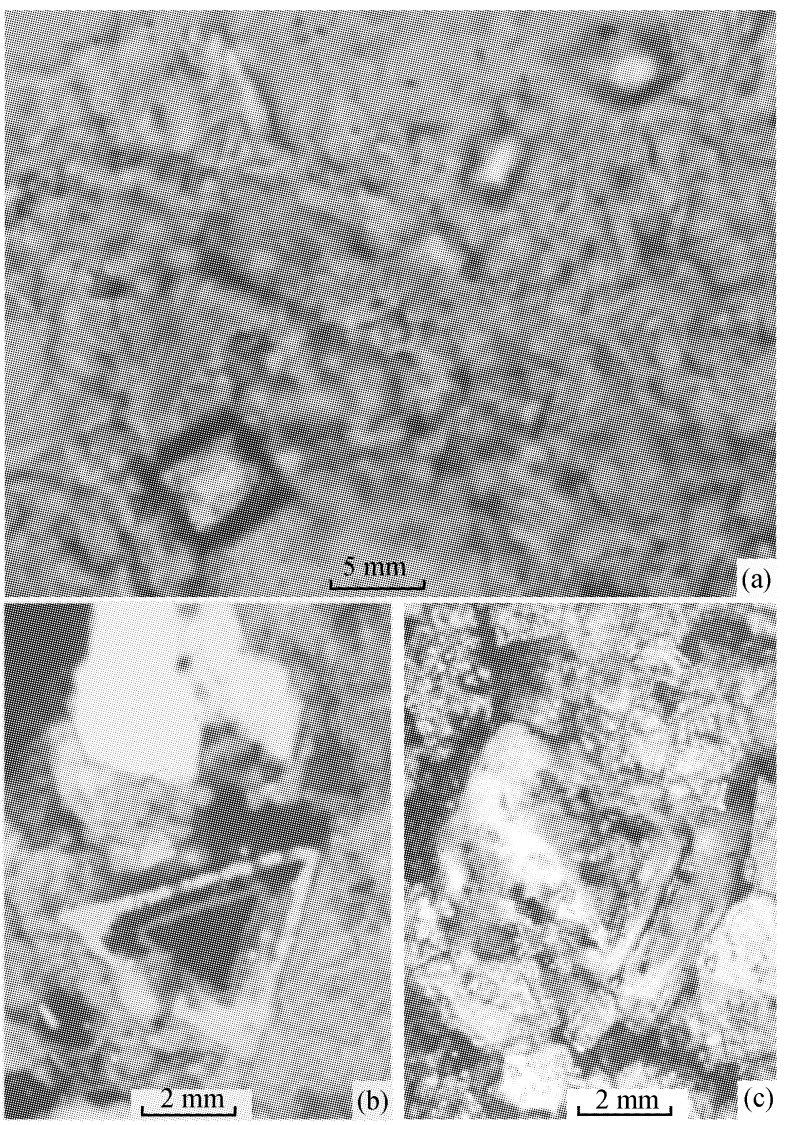

图 3 大林子组蒸发岩系中溶解石盐假晶发育特征

(JDS-14)

(a) 微粒石盐假晶(具共轴环带边的玉髓充填); (b) 具共轴环带石盐假 晶立方体的三角断面; (c) 完好的具共轴的立方石盐假晶(玉髓充填)

上述比较沉积学分析为认识华北早古生代盐盘 沉积与海平面变化周期以及与其相关的封闭泻湖洼 地干旱期的潜水位变化(图 1 中的 DPS)模式提供了有 价值的借鉴. 无论是现代还是古生代的盐盘层序都 可以划分出洪泛-海泛期(淡化湖或正常海)、蒸发浓 缩期(咸化泻湖或盐湖)和干旱期(潜水位下降过程中 形成的干盘状洼地). 图 4 为大林子组盐盘及渗流管 状构造的形成模式, 代表盐盘沉积层序的综合演化 过程, 不代表某一微层序实际状况, 但是总的演化趋 势是由下而上从咸化泻湖至正常海.

\section{4 讨论}

据上述研究, 我们认为《华北》 ${ }^{[1]}$ 一文所涉及的 大林子组“且齿构造”(Molar tooth carbonates struc

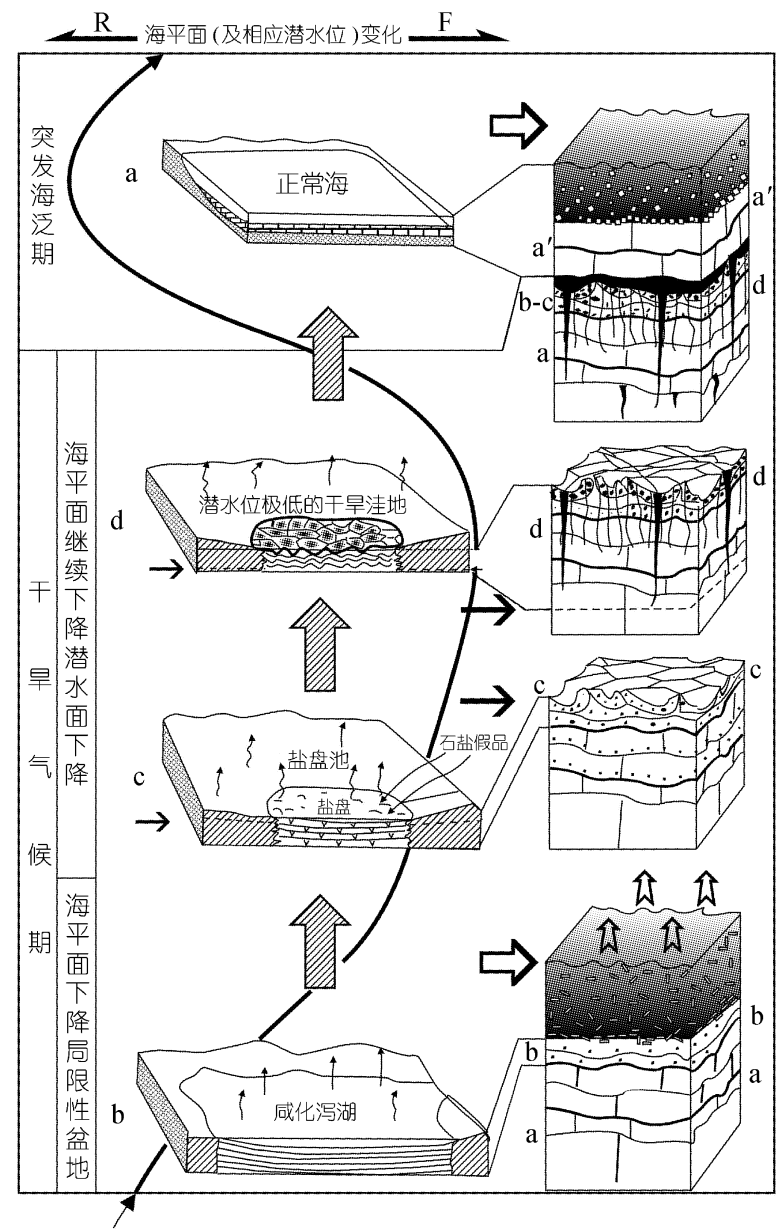

图 4 大林子组蒸发盐岩系沉积旋回、气候周期及渗流构 造形成模式示意图

a: 正常海泛沉积; b: 咸化泻湖期沉积; c: 盐盘池期沉积; d: 潜水位下 降期渗流构造. 单箭头示潜水位位置, 空心箭头示海平面位置

ture), 应为典型的溶解(渗流)状构造.

（ｉ）《华北》一文所指的大林子组“震积岩-臼齿 构造”, 实际上是发育于具盐溶成因的碎屑砂泥岩中 的溶解 (渗流)状构造(Dissolution structure $)^{[2,3,6,8 \sim 11]}$, 无论从成因还是从岩类上，与臼齿构造碳酸盐岩是 根本不同的两大类别, 不能相提并论. 大林子组的盐 溶岩系是蒸发盐泻湖盆地在干旱气候条件下形成的 盐溶序列，其中的管状构造是由于海平面下降到低 于盆地沉积表面以下和相应潜水位下降波动过程中, 沿干裂纹交叉缝隙由大气雨水-溶解渗流作用形成的 大气淡水溶解渗流状构造. 其形成环境与作用机制 
都与地震作用无关, 因而大林子组的层序并不存在 “震积岩序列”。渗流管构造受海平面升降和气候周 期变化控制, 特别是受盆地潜水位下降的控制 (见图 4), 是蒸发盐干旱事件和海平面、潜水位下降的证据. 渗流状构造的长度代表干旱气候时期盆地潜水面下 降的深度. 最大的干旱时期潜水面下降的深度最大, 因此可以形成较粗和较长的渗流状物. 渗流中充填 物主要是海平面下降期陆源或干旱萨布哈潮上陆源 泥粉砂及盐溶形成的石盐假晶等沉积物. 无论从该 沉积构造的物质组成、构造形态、还是从其产出背景 和成因都与臼齿构造没有相似之处. 至少说明: 所谓 华北地台寒武系存在 “震积岩和震积岩序列”、“地震 活动期” 这一结论，其依据是不足的.

(ii) 关于臼齿构造的成因问题有多种观点, 但 是, 不论哪种观点, 都把 “臼齿构造”一词的应用限 于碳酸盐岩, 都肯定它发育在元古代, 并具有重要的 时限意义和全球对比意义(据文献[12], 臼齿构造碳 酸盐岩的分布具有全球性, 并已证明它们全部属于 元古代). $S$ mith ${ }^{[12]}$ 和 James $^{[13]}$ 及本文作者 ${ }^{1)}$ 都曾详细 地论述过臼齿构造碳酸盐岩为前寒武纪时限性沉积. James ${ }^{[13]}$ 还特别指出, 臼齿富集在元古代碳酸盐中, 但罕见于显生宙岩石中. Smith ${ }^{[12]}$ 称臼齿碳酸盐岩可 能作为前寒武纪生物地层标志物. 本文的讨论意义 还在于弄清元古代以后是否罕见兒齿碳酸盐岩的重 大问题. 通过本文的讨论, 无疑更加清楚地表明：白 齿构造碳酸盐岩具时限性意义, 并很可能为早期地 球历史和生命演化提供重要依据和线索.

致谢 本文得到杨遵仪院士的支持和关心, 法国 R. Bourrouilh, F. B. Lejan 和加拿大 D. G. F. Long 教授参加了野外 考察并进行了有益的交流，特此致谢。本工作受国家自然 科学基金 (批准号：40172043)、国际地质对比计划 IGCP447(批准号: SC/GEO/546/447) 和科学技术部国际科 技合作重点项目(批准号: 2001CB711002)资助.

\section{参考文献}

1 乔秀夫, 高林志. 华北中新元古代及早古生代地震灾变事件及 与 Rodinia 的关系. 科学通报, 1999, 44(16): 1753 1757
2 Meng Xianghua, Ge Ming, Liu Yongqing. The general division and sequence framework of the Sinian-Ordovician second-order cyclic sequence and deposuites in China. In: Meng Xianghua, Ge Ming, eds. Sinian-Ordovician Paleogeography, Cyclicity-Rhythm and Sedimentary Event of China. Beijing: International Academic Publishers, 1996. $1 \sim 21$

3 Meng Xianghua, Ge Ming. The new genetic type of lowstand wedge in carbonate platform - - halite saltpan lowstand system tract of Early Cambrian in the north China platform. In: Meng Xianghua, Ge Ming, eds, Sinian-Ordovician Paleogeography, Cyclicity-Rhythm and Sedimentary Event of China. Beijing: International Academic Publishers, 1996. $170 \sim 174$

4 洪作民, 黄镇福, 刘效良. 辽东半岛上前寒武系地质. 北京: 地 质出版社, 1991. 26 38

5 何镜宇, 孟祥化. 沉积岩和沉积相模式及建造. 北京: 地质出版 社, 1989. 262

6 Ge Ming, Liu Yongqing, Meng Xianghua. The depositional sequences and the evolutionary history of the north China carbonate platform of Early Paleozoic. In: Ge Ming, Liu Yongqing, Meng Xianghua, eds. Field Trip Guide of 30th International Geological Congress. Beijing: Geological Publishing House, 1996. $4 \sim 6$

7 刘印环, 王建平, 张海清, 等. 河南的寒武系和奥陶系. 北京: 地质出版社, 1994. 6 28

8 Tucker R M. Giant polygons in the Triassic salt of heshire, England: A thermal contraction model for their origin. Journal of Sedimentary Petrology, 1981, 51: $779 \sim 786$

9 Lowenstein T K, Hardie L A. Criteria for the recognition of salt-pan evaporates. Sedimentology, 1985, 32(5): $627 \sim 644$

10 Wezel F C. Structural features and basin tectonics of the Tyrrhenian Sea. In: Stanley D J, Wezel F C, eds. Geological Evolution of the Mediterranean Basin. New York: Springer-Verlag, 1985. 153 194

11 Lugli S, Schreiber B C, Triberti B. Giant polygons in the Redlmonte Mine (Agregento Sicily): Evidence for the desiecation of a messinian halite basin. Journal of Sedimentary Research, 1999, 69(3): $761 \sim 771$

12 Smith A G. The origin and deformation of some "molar-tooth" structure in the Precambrian belt-purcell supergroup. Journal of Geology, 1968, 76: $426 \sim 443$

13 James N P. Molar-tooth carbonates: Shallow subtidal facies of the Mid- to Late Proterozoic. Journal of Sedimentary Research, 1998, 68(5): $716 \sim 722$

(2001-12-10 收稿)

1) Meng Xianghua, Ge Ming, Yang Zunyi. Chart of cyclic sequence, events, sedimentary evolution and the developmental features of molar tooth carbonates in N. China. IGCP project $447-\frac{1}{-}$ its main object in Ulrich G Wortmann, Hanspeter Funk, abstract and programme. Davos: IAS 200121 st Meeting, 2001. $171 \sim 172$ 